\title{
First evaluation of semidirect recycling methods for the reclamation of cemented carbides based on a literature survey
}

\author{
${ }^{1}$ CD Laboratory for Extractive Metallurgy of Technological Metals, Nonferrous Metallurgy, Montanuniversitaet Leoben, \\ Franz-Josef-Str. 18, A-8700, Leoben, Estíria, Austria \\ e-mail: gregor.kuecher@unileoben.ac.at \\ ${ }^{2}$ CERATIZIT Austria GmbH, Metallwerk-Plansee-Str. 71, A-6600, Reutte, Tyrol ,Austria \\ e-mail: christoph.czettl@ceratizit.com
}

\begin{abstract}
At the moment the industrially applied techniques for cemented carbide reclamation feature several deficiencies. Depending on the process route, obstacles consist in high energy and chemical consumption (indirect recycling methods) or a deterioration of the recycled product in comparison with the primary material (direct recycling approach). Therefore, an alternative middle course provided by semidirect recycling processes seems promising. Accordingly, the coating materials as well as the binder metals are leached off the substrate keeping the hard phase unaffected and ready for reuse. However, the literature reports various difficulties like the slow dissolution of the binder, particularly if the scrap consists of larger pieces, contains a low binder metal perecentage or a small grain size. Furthermore, oxidation of the cemented tungsten occurs as an undesired reaction, causing even slower lixiviation and a contamination of the recycled product.

Due the fact of an inexistent comparable systematic analysis of the semidirect recycling procedures, this article deals with a primary screening of potential combinations of acids, additives and oxidizing agents found in a literature survey. All experiments took place under the same conditions in a temperature controlled double-walled reaction vessel, varying only the molar concentrations of the different species as used in literature. A crucial point comprised of the development of an appropriate sample preparation, which allowed a simplification of the analysis along with its applicability in future kinetic investigations of selected solutions. As a result, promising combinations of chemicals are ready for further investigations determined by penetration depth and abrasion of the hard metal substrate. Successfully applied mixtures incorporate acids such as $\mathrm{HNO}_{3}$ and $\mathrm{HCl}$ followed by some organic acids, all combined with $\mathrm{H}_{2} \mathrm{O}_{2}$ as oxidant.
\end{abstract}

Keywords: semidirect hard metal recycling, reclamation of cemented carbides, leaching of cobalt

\section{INTRODUCTION}

In the past decade China dominated the world production of tungsten ore concentrate with a share of $80 \%$ of the total annual amount $[1,2]$. Considering the fact that the hard metal production utilizes about 50-60 \% of the tungsten, the recycling of cemented carbide scrap should provide a substantial contribution for a more independent cost saving supply [3]. Currently most of the industrially applied techniques for cemented carbide reclamation rest upon on a pretreatment and feed into the primary route (indirect recycling) or the zinc-process (direct route) [2-5].

However, each of the mentioned processes displays several deficiencies. The main issue of the indirect pathway consists of high energy and chemical consumption. At the moment an oxidation process with a combined hydrometallurgical digestion and an alkaline salt fusion treatment constitute the main representatives of this route. Both methods produce water-soluble $\mathrm{Na}_{2} \mathrm{WO}_{4}$ and further treatment basically follows the primary production (solution purification, SX, APT crystallization, reduction, carburation) $[3,4]$.

In the zinc-process, the coating material's conditioning displays a challenge, since the films hinder the necessary diffusion of zinc. Additionally, these layers persist in the reclaimed material and act as contaminant. Due to the treatment, the oxygen content rises while the carbon level decreases which has to be considered for a new hard metal mixture as a result of the changed sintering behavior [6]. Consequently, the 
production of hard metals typically just applies a portion of 20-50 \% zinc recyclate beside virgin powder [5].

These circumstances encourage evaluating the semidirect recycling as an alternative middle course. By doing so, the coating materials and binder metals are leached while the hard phase remains unaffected and stays ready for reuse. Subsequent ordinary hydrometallurgical processes reclaim the leached binder out of the solution $[3,7,8]$. In the last years few publications examined studies concerning the semidirect pathway but without solving the obstacles.

SCHIESSER [7] investigated the dissolution characteristics of cobalt out of uncoated hard metals in acetic acid with and without oxygen and for comparison purposes in sulfuric acid. Respectively, small grain size, low binder content and partly oxidized WC cause slow dissolution rates. EDTMAIER, et al. [9] specified that an oxygen partial pressure above 5 bar particularly leads to an oxidation of WC in acetic acid solutions. According to the United States Patent 3,947,555, invented by MAC INNIS and VANDERPOOL [10], glacial acetic acid at boiling temperature dissolves cobalt, iron or nickel from metal carbide powders in $1-5 \mathrm{~h}$.

In agreement with the United States Patent 3,438,730 from SHWAYDER [11], the long leaching time of strong corrosive acids makes the industrial implementation uneconomical and the author lists various acids with specific weight recoveries within $24 \mathrm{~h}$. Corresponding to the invention, autogenous milling in a weak phosphoric acid especially combined with $\mathrm{H}_{2} \mathrm{O}_{2}$ exhibits advantageous characteristics.

Likewise GÜRMEN and FRIEDRICH [12] studied the nature of a dilute $\mathrm{HNO}_{3}$ for dissolving $\mathrm{Co}, \mathrm{Fe}$ and Ni from a pulverized hard metal fraction with varying parameters like temperature, concentration, grain size, reaction time, solid to liquid ratio and stirring speed. Under optimal conditions, the reported leaching residue mainly consists of WC and TiC with traces of Co. The German Patent Application DE 2726817 A1 [8] discloses a method for reclaiming $\mathrm{Ta}(\mathrm{Nb}) \mathrm{C}-\mathrm{WC}-\mathrm{TiC}$ mixed carbides from hard metal scraps in 10-30 wt$\% \mathrm{HNO}_{3}$ at $60-90{ }^{\circ} \mathrm{C}$. As stated, WC oxidizes to $\mathrm{H}_{2} \mathrm{WO}_{4}$, if not bound in a mixed crystal. In contrast MEYER [8] described a concentration of 10-30 wt- $\%$ (equals 1.7-5.6 mol/l) $\mathrm{HNO}_{3}$ and GÜRMEN and FRIEDRICH [12] just 0.5-1.5 mol/l. KOJIMA, et al. [13] discovered that a $6 \mathrm{~mol} / \mathrm{l} \mathrm{HCl}$ aqueous solution at $110{ }^{\circ} \mathrm{C}$ suits ideally for dissolving the binder out of WC-Co cemented carbides compared to $\mathrm{H}_{2} \mathrm{SO}_{4}$ and $\mathrm{HNO}_{3}$. In order to receive a powder comparable to virgin state, an oxidation of the reclaimed powder during the milling and drying process must be avoided. Moreover, the patent WO 99/07905 of KOPYLOV and POLYAKOV [14] explains the advantageous application of a hydrochloric acid of $28-37 \mathrm{wt}-\%$ at a temperature up to $90{ }^{\circ} \mathrm{C}$ for recovering a high purity powder. This combination of parameters enables the detaching of thin $\mathrm{TiN}$ and $\mathrm{TiC}$ layers, but not $\mathrm{Al}_{2} \mathrm{O}_{3}$. In combination with a secondary mechanical disintegration of the weakened substrate, the mentioned process exhibits a comparatively low energy consumption. They also criticize about SHWAYDER [11] that $\mathrm{H}_{3} \mathrm{PO}_{4}$ partially oxidizes the WC phase and that phosphates precipitate accompanied by an insufficient binder extraction.

As specified above, some uncertainties emerge from the mentioned patents and publications as well as challenges for a suitable technical process scheme. Hence, the most demanding issues comprise of the oxidation of the WC phase, long leaching times, precipitation of unwanted phases, remaining cobalt, the removal of coatings and optionally the pulverization of hard metals scrap fractions. Unfortunately, milling as a pretreatment step for cemented carbide residues proves to be fairly laborious. Therefore, this study deals with a primary evaluation of possible hydrometallurgical methods for overcoming these problems. The present report explores several combinations of acids, additives and oxidizing agents. Supplementarily it discloses a suitable investigation methodology for future kinetic investigations of lixiviation.

\section{MATERIALS AND METHODS}

All presented experiments utilized the same type of cutting inserts with the characteristics according to Table 1 and provided by courtesy of CERATIZIT Austria GmbH. In conformity with ISO 1832, the inserts comprised of a quadratic base area with a $12 \mathrm{~mm}$ side length including a radius of $1.2 \mathrm{~mm}$ at each corner and a height of $4 \mathrm{~mm}$. As pointed out, the development of an adequate sample preparation should facilitate future kinetic investigations of the leaching process. Generally, changes of concentration, mass or volume document a reaction process over time. For a chemical kinetic analysis the model complies with the observed time dependency considering the geometry of the sample. Due the fact that a multidimensional conversion of the sample results in a more complex kinetic equation, the assignment involved a reduction to a one-dimensional case. HABASHI [15] or LEVENSPIEL [16] allocate more details about kinetic reaction theory. 
Table 1: Properties of the used cutting inserts

\begin{tabular}{l|l}
\hline SPECIFICATION & DIMENSION \\
\hline Grain size & Medium \\
\hline Co & 6.0 wt-\% \\
\hline Composite carbides & 0.6 wt-\% \\
\hline WC & 93.4 wt- $\%$ \\
\hline Geometry & SNUN120412 - ISO 1832 \\
\hline Condition & Sintered, unmachined \\
\hline
\end{tabular}

Thus, an embedding machine implanted a cutting insert in a transparent non-conducting thermoplast from Struers, trade name ClaroFast, which mainly consists of methacrylate. Afterwards, grinding and polishing served for obtaining a defined reaction surface. A $1 \mu \mathrm{m}$ diamond paste suspension provided the last polishing step. To determine the height between the surfaces before and after leaching, the superglue ergo 5012 universal (cyanoacrylate) covered about one-third of the final specimen surface. Figure 1 displays such a sample. Both the used thermoplast as well as the superglue fulfilled the beforehand realized chemical and thermal resistance tests (not presented here).

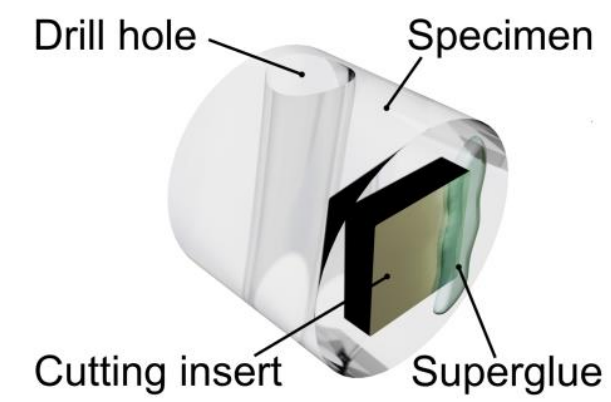

Figure 1: 3D model of the prepared test samples with superglue

All experiments were performed in a $250 \mathrm{ml}$ double-walled reaction vessel made of borosilicate glass with a cap fixed by a steel clamp. The cap comprising three ground glass joints 14/23 and one 29/32 according DIN 12242 allowed the positioning of one specimen via a bar in the center. The smaller joints contained the temperature control sensor, the reflux condenser and the purging nitrogen supply. A magnetic stirrer at about $200 \mathrm{~min}^{-1}$ permitted the uniform mixing of the leachant.

Furthermore, a circulation thermostat enabled the realization of the experiments at a constant temperature of $50{ }^{\circ} \mathrm{C}$ for a period of $4 \mathrm{~h}$. All the test solutions according to Table 2 were prepared directly before application. When the total amount of $200 \mathrm{ml}$ of these mixtures in the reactor reached the desired temperature, the test started by immersing the specimen from the cap into the liquid. 
Table 2: Solutions for screening tests

\begin{tabular}{l|l|l|l|l|l|l}
\hline NO. & SPECIES 1 & $\mathbf{C}$ (mol/I) & SPECIES 2 & $\mathbf{C}$ (mol/l) & SPECIES 3 & $\mathbf{C}(\mathbf{m o l} / \mathbf{l})$ \\
\hline 01 & $\mathrm{HCl}$ & 6.0 & - & - & - & - \\
\hline 02 & $\mathrm{HCl}$ & 1.0 & $\mathrm{H}_{2} \mathrm{O}_{2}$ & 5.0 & - & - \\
\hline 03 & $\mathrm{H}_{3} \mathrm{PO}_{4}$ & 2.3 & - & - & - & - \\
\hline 04 & $\mathrm{H}_{3} \mathrm{PO}_{4}$ & 2.3 & $\mathrm{H}_{2} \mathrm{O}_{2}$ & 5.0 & - & - \\
\hline 05 & $\mathrm{HNO}_{3}$ & 0.5 & - & - & - & - \\
\hline 06 & $\mathrm{HNO}_{3}$ & 0.5 & $\mathrm{H}_{2} \mathrm{O}_{2}$ & 5.0 & - & - \\
\hline 07 & $\mathrm{CH}_{2} \mathrm{O}_{2}$ & 1.5 & - & - & - & - \\
\hline 08 & $\mathrm{CH}_{2} \mathrm{O}_{2}$ & 1.5 & $\mathrm{H}_{2} \mathrm{O}_{2}$ & 5.0 & - & - \\
\hline 09 & $\mathrm{C}_{2} \mathrm{H}_{4} \mathrm{O}_{2}$ & 3.5 & - & - & - & - \\
\hline 10 & $\mathrm{C}_{2} \mathrm{H}_{4} \mathrm{O}_{2}$ & 3.5 & $\mathrm{H}_{2} \mathrm{O}_{2}$ & 5.0 & - & - \\
\hline 11 & $\mathrm{H}_{2} \mathrm{SO}_{4}$ & 0.5 & $\mathrm{KMnO}_{4}$ & 0.1 & - & - \\
\hline 12 & $\mathrm{NH}_{4} \mathrm{OH}$ & 3.0 & $\mathrm{C}_{2} \mathrm{H}_{4} \mathrm{O}_{2}$ & 0.5 & $\mathrm{H}_{2} \mathrm{O}_{2}$ & 5.0 \\
\hline 13 & $\mathrm{NH}_{4} \mathrm{OH}$ & 3.0 & $\mathrm{C}_{6} \mathrm{H}_{8} \mathrm{O}_{7}$ & 0.1 & $\mathrm{H}_{2} \mathrm{O}_{2}$ & 5.0 \\
\hline 14 & $\mathrm{H}_{2} \mathrm{O}_{2}$ & 5.0 & - & - & - \\
\hline
\end{tabular}

After leaching, deionized water and 2-propanol rinsed the samples. In order to separate the embedding material from the hard metal substrate, a mechanical force applied via jaws of a vice broke the brittle synthetics without damaging the cutting inserts. The further preparation consisted of an ultrasonic cleaner conditioning with 2-propanol. Subsequently a cutting machine divided each sample in two parts, each of them being at least one third. A piece turned by $90^{\circ}$ was embedded in PolyFast (electroconductive) from Struers. Finally, the ground and polished samples $(1 \mu \mathrm{m}$ finish) reached a state ready for analyses in an optical and a scanning electron microscope. Figure 2 summarizes the whole routine as stated beforehand.

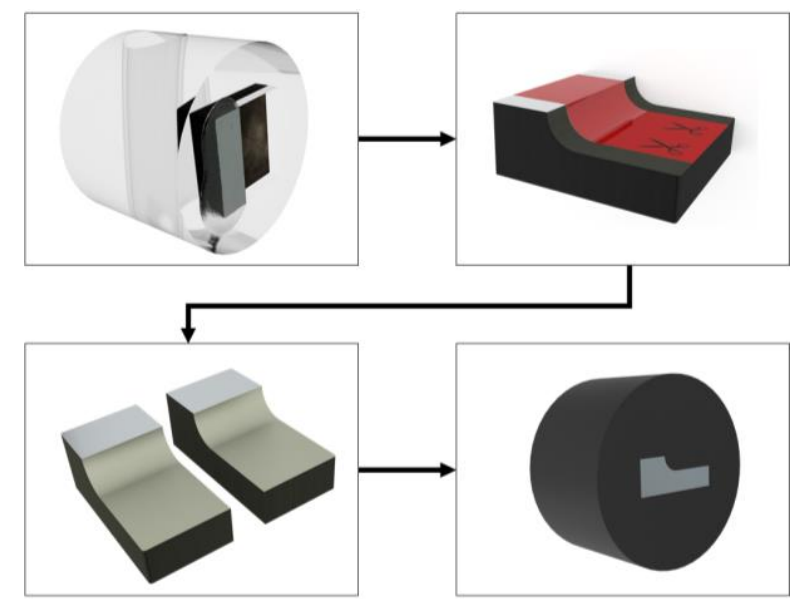

Figure 2: Schematic illustration of the preparation procedure for an evaluation of the penetration depth

\section{RESULTS}

As pointed out in the prior chapter, some substrate was removed in relation to the original surface in several experiments, but due to very small quantities of fine particles no recovery took place. Nevertheless, the superglue coating allowed a quantification of absent material. The analysis by dark field microscopy additionally revealed the depleted binder (zone 1) as well as the transition area (zone 2) as indicated in the Figure 3. 

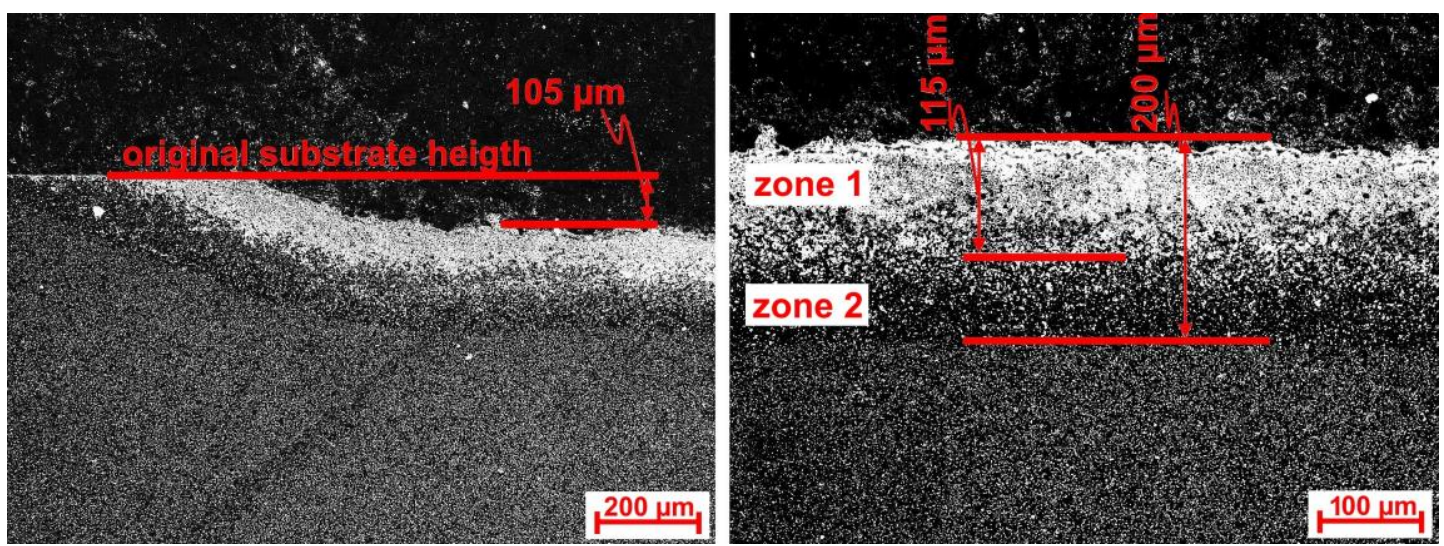

Figure 3: Dark field microscopy picture of experiment no. 06, (left) illustration of the worn substrate, (right) evaluation of the penetration depth with transition zone

The executed experiments without $\mathrm{H}_{2} \mathrm{O}_{2}$ did not reveal any detectable influence under the presented parameters $\left(\mathrm{t}=4 \mathrm{~h}, \mathrm{~T}=50^{\circ} \mathrm{C}, 200 \mathrm{ml}\right)$ aside from a few single detached $\mathrm{WC}$ grains. Hence, Table 3 lists all received results for solutions with hydrogen peroxide determined by the optical microscope.

Table 3: Summary of all successful leaching experiments, quantified by dark field microscopy

\begin{tabular}{l|l|l|l|l}
\hline NO. & WORN SUBSTRATE $(\boldsymbol{\mu m})$ & ZONE $\mathbf{1}(\boldsymbol{\mu m})$ & ZONE $\mathbf{2}(\boldsymbol{\mu m})$ & SUM Z1+2 $(\boldsymbol{\mu m})$ \\
\hline 02 & 135 & 110 & 90 & 200 \\
\hline 04 & 40 & 65 & 55 & 120 \\
\hline 06 & 105 & 115 & 85 & 200 \\
\hline 08 & 0 & 75 & 45 & 120 \\
\hline 10 & 0 & 100 & 40 & 140 \\
\hline 12 & 0 & 0 & 30 & 30 \\
\hline 13 & 0 & 15 & 0 & 15 \\
\hline 14 & 0 & 10 & 0 & 10 \\
\hline
\end{tabular}

The comparision in Figure 4 discloses on the left-hand side one representative of inorganic acids (left) in relation to an organic acid (right), each with oxidant. Respectively, the inorganic mixtures showed a more aggressive attack of binder and grain boundaries. Consequently, the WC grains exhibit sharp edges and more defined surfaces, while the composite additionally misses some grains. In contrast, the organic acids with oxidant behaved differently. Some crystals still feature the original surface caused by the grinding and polishing steps beside inaccurate boundaries between the crystallites. Solely a few grains are removed from the substrate surface.
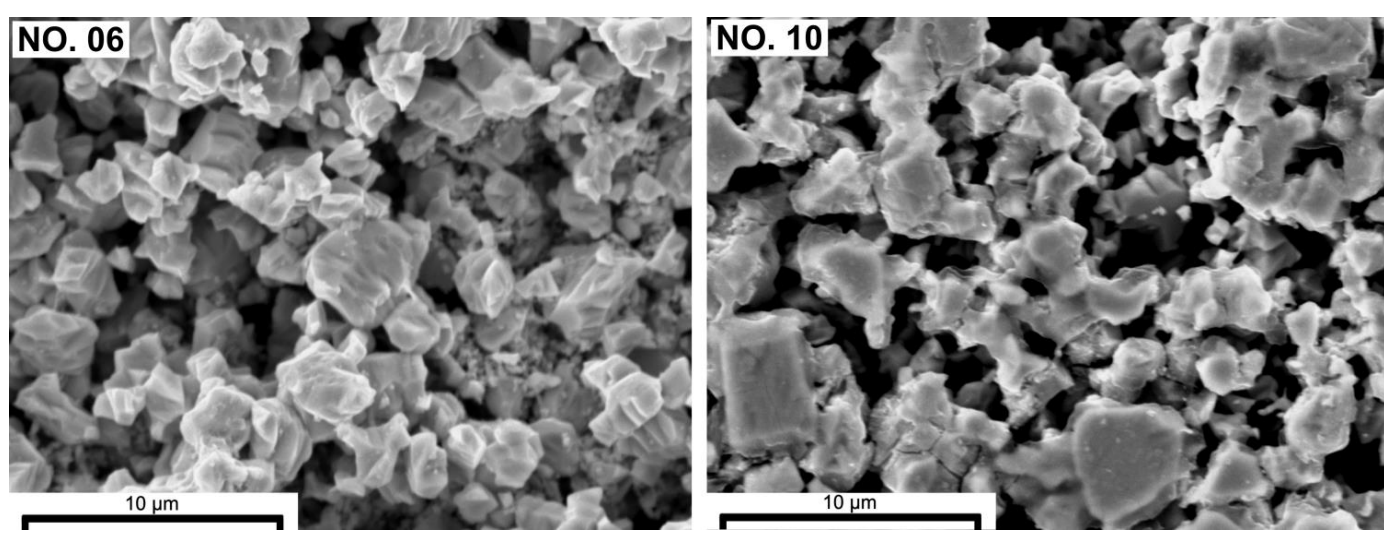

Figure 4: SEM-SE topological pictures of the surfaces of leached substrates, experiment no. 06 (left) and no. 10 (right) 


\section{DISCUSSION}

Depending on the respective acid, the experiments applied different molar concentrations. Therefore, a direct comparison does not seem appropriate. Nevertheless, an interesting outcome of the screening displays that no acid on its own showed a measureable amount of leached Co in $4 \mathrm{~h}$. Only acids combined with $\mathrm{H}_{2} \mathrm{O}_{2}$ as oxidation agent accomplished a noteworthy leaching. The oxidant by itself just caused a depth of about $10 \mu \mathrm{m}$, even though $\mathrm{H}_{2} \mathrm{O}_{2}$ behaves as weak acid. The most promising combinations comprise of acids in combination with $\mathrm{H}_{2} \mathrm{O}_{2}$. According to the results, the inorganic acids $\mathrm{HCl}$ and $\mathrm{HNO}_{3}$ showed most favorable leaching characteristics followed by acetic and formic acid. Remarkably no complex mixture (no. 11-13) revealed an intense influence on the substrate. Due to the small sample size no determinable residue remained, for which reason it stays unclear if the worn WC grains were dissolved or loosened. However, the organic acid mixtures did not demonstrate any detached substrate, hence these seem to possess a more selective leaching behavior. In general, the studies with optical microscopy disclosed a preferential leaching of cobalt versus WC.

In relation to literature (introduction) following points stand out. The dissertation of SCHIESSER [7] and the associated publication of EDTMAIER, et al. [9] illustrate that the leaching in acetic acid with oxygen for a cube of $1 \mathrm{~cm}^{3}$ needs roughly 30-160 days depending on substrate and leaching parameters. GÜRMEN and FRIEDRICH [12] investigated the leaching of pulverized hard metal in diluted $\mathrm{HNO}_{3}$, whereas KOJIMA, et al. [13] examined the lixiviation of a cylindrical cutting insert with a cross-section of $15 \mathrm{~mm}$, a height of $5 \mathrm{~mm}$ and $20 \% \mathrm{Co}$ in $\mathrm{HCl}$. In both cases the leaching needed time from a few hours to less than a day. The patent of MEYER [8] refers to powdered hard metal fractions in an application example, while MAC INNIS and VANDERPOOL [10] specify uncemented tungsten carbide powder in their claims. SHWAYDER [11] performed the lixiviation in a rotating container whereas KOPYLOV and POLYAKOV [14] remark the weakening of the substrate during leaching by subsequent mechanical disintegration.

To summarize the quoted statements, the leaching of hard metals takes several days to months if the treated fraction is not pulverized, contains a low amount of binder, stays cemented or is not mechanically stressed. Pulverization of hard metals forms a complex task, since this category of materials serves for machining others. Different carbide qualities with lower binder contents and smaller grains also exist. Hence a proper recycling technique should be able to treat a wider range of compositions and grades.

On the contrary, acids including an oxidant influenced a depth of more than $300 \mu \mathrm{m}\left(\mathrm{HCl}+\mathrm{H}_{2} \mathrm{O}_{2}\right.$ and $\mathrm{HNO}_{3}+\mathrm{H}_{2} \mathrm{O}_{2}$ ) of a cutting insert with lower amount of binder metal and medium grain size in just $4 \mathrm{~h}$ without any additional mechanical wear during the present investigation. Furthermore, this achievement succeeded in realizing a substantial leaching depth without elevated temperature close to the boiling point.

\section{CONCLUSIONS}

By just screening no final answer concerning the selectivity of cobalt leaching from a cemented carbide substrate can be derived, nor about the influencing parameters like concentrations, temperature or solid to liquid ratio. Apparently, at a temperature of $50{ }^{\circ} \mathrm{C}$ acids with $\mathrm{H}_{2} \mathrm{O}_{2}$ should be taken into account for a proper approach of a selective lixiviation of cobalt out of lumpy hard metals. The obtained results hypothesize, that complete binder removal of a $1 \mathrm{~cm}^{3}$ cube can be achieved in less time than stated in literature. Furthermore, organic acids showed a more selective leaching of cobalt and no unfavorable ions are introduced by them into the system. Therefore, if the recovery of cobalt takes places via precipitation of an organic salt, a cleaner product will be obtained. Likewise the WC product remains free of inorganics. Additionally, the risk of occurrence of harmful vapors during leaching is reduced in comparison to inorganics like $\mathrm{HNO}_{3}$ or $\mathrm{HCl}$.

\section{ACKNOWLEDGMENTS}

The financial support by the Austrian Federal Ministry of Science, Research and Economy and the National Foundation for Research, Technology and Development is gratefully acknowledged.

\section{BIBLIOGRAPHY}

[1] SHEDD, K. B., U.S. GEOLOGICAL SURVEY, http://minerals.usgs.gov/minerals/pubs/commodity/tungsten/myb1-2013-tungs.pdf. Accessed in March 2016. [2] PITFIELD, P., BROWN, T., GUNN, G., et al., BRITISH GEOLOGICAL SURVEY, https://www.bgs.ac.uk/downloads/start.cfm?id=1981. Accessed in March 2016.

[3] GILLE, G., MEIER; A., "Recycling von Refraktärmetallen", In: Recycling und Rohstoffe, v. 5, pp. 537- 
560, TK-Verlag, 2012.

[4] SHEDD, K. B., U.S. GEOLOGICAL SURVEY, http://pubs.usgs.gov/circ/circ1196-R/. Accessed in June 2014.

[5] KARHUMAA, T., KURKELA, M., "Review of the Hardmetal Recycling Market and the Role of the Zinc Process as a Recycling Option", In: Proceedings of the $18^{\text {th }}$ International Plansee Seminar, HM13/111, Reutte, Austria, 3-7 June 2013.

[6] ZEILER, B.; "Recycling von Hartmetallschrott", In: Hartstoffe, Hartstoffschichten, Werkzeuge, Verschleißschutz, Werkstoff-Informationsgesellschaft, pp. 283-303, 1997.

[7] SCHIESSER, R., Wertstoffrecycling wolframhältiger Sekundärrohstoffe, thesis Ph.D., TU Wien, Wien, 2003.

[8] MEYER, H., "Verfahren zur Rückgewinnung von $\mathrm{Ta}(\mathrm{Nb}) \mathrm{C}-\mathrm{WC}-\mathrm{TiC}-M i s c h u n g e n ”$, patent,

DE 2726817 A1, 1979.

[9] EDTMAIER, C., SCHIESSER, R., MEISSL, C., et al., "Selective removal of the cobalt binder in WC/Co based hardmetal scraps by acetic acid leaching", Hydrometallurgy, v. 76, n. 1-2, pp. 63-71, January 2005.

[10] MAC INNIS, M.C., VANDERPOOL C., "Process for Recovering Tungsten from Tungsten Carbides containing an Iron Group of Metals", patent, US 3,887,680, 1975.

[11] SHWAYDER, W.M., "Method of disintegrating sintered hard carbide masses", patent, US 3,438,730, 1969.

[12] GÜRMEN, S., STOPIC, S., FRIEDRICH, B., "Recovery of submicron cobalt-powder by acidic leaching of cemented carbide scrap", In: Perspectives of the non-ferrous metals industry in an area of consolidation, European Metallurgical Conference, 1725-1740, Dresden, Germany, 18-21 September 2005.

[13] KOJIMA, T., SHIMIZU, T., SASAI, R., ITOH, H., "Recycling process of WC-Co cermets by hydrothermal treatment", Journal of Materials Science, v. 40, n. 19, pp. 5167-5172, October 2005.

[14] KOPYLOV, N., POLYAKOV, B., "Method of disintegrating sintered hard metal carbide bodies and recovering hard metal carbide powder", patent, WO 99/07905 A1, 1999.

[15] HABASHI, F., Extractive Metallurgy, General Principles, 1 ed., New York, Gordon and Breach, 1969.

[16] LEVENSPIEL, O., Chemical reaction engineering, 3 ed., New York. Wiley, 1999. 